\title{
EFFECT OF USING EXTERNAL GFRP PLATES ON STRUCTURALLY DEFICIENT RC BEAMS
}

\author{
Hau Y. Leung and Ramapillai V. Balendran \\ Dept of Building \& Construction, City University of Hong Kong, \\ Tat Chee Avenue, Kowloon, Hong Kong SAR, China.E-mail: bchyl@cityu.edu.hk
}

Received 19 Sept 2002; accepted 15 Dec 2002

\begin{abstract}
This paper presents some experimental results on the behaviour of flexure- and shear-deficient RC beams strengthened with external glass fibre reinforced polymer (GFRP) plates. Ten number of $2,5 \mathrm{~m}$ long over-designed, unplated under-design and plated under-designed beams were examined under four-point bending condition. Experimental results indicated that use of GFRP plates enhanced the strength and deformation capacity of the structurally deficient beams by altering their failure modes. Application of side plates on shear-deficient RC beams appeared to be more effective than using bottom plates on flexure-deficient RC beams. However, without any improvement on concrete compressive capacity, additional shear capacities provided to the beams under the action of side plates increased the likelihood of beam failure by concrete crushing. Simultaneous use of bottom and side plates on flexure- and sheardeficient RC beams could result in reduced deflection. The change in the neutral axis depth and GFRP strain was also addressed.
\end{abstract}

Keywords: concrete, RC beams, strengthening, GFRP, external plates, flexure, shear.

\section{Introduction}

Corrosion of steel reinforcement in conventional reinforced concrete (RC) structures has long been a major issue to building engineers. It may cause a lot of problems ranging from minor unsightly cracks to major structural collapse. In addition to corrosion, various extent of structural deficiency may be the results of bad workmanship, material ageing and deterioration, environmental attack, change of usage of building, and overloading of structures. Also, old structural design accepted in the past may not comply with current design practices, building codes and safety guidelines. All these factors contribute to an urgent need for an easy-to-apply, non-metallic, high-strength and durable material. Recently, fibre reinforced polymer (FRP) which consists of fibres embedded in a polymeric matrix has been found to be of low density, non-corrosive and to possess a high strength-to-weight ratio, and thus it has been widely suggested to be used in RC design by many researchers and engineers [1]. In practice, FRP can be incorporated into concrete structures in different forms, like embedded bars, meshes, gratings and external plates [2]. Among them, external use of FRP sheet or plate is the most convenient, fast, effective and promising way of rehabilitation and strengthening.

Strengthening of old and damaged RC beams is normally much more economical than demolition or re- construction. This is particularly true to historical buildings because the change in size and shape of structural member can be kept to a minimum. With regard to the above-mentioned reasons, defective $\mathrm{RC}$ beams are largely considered to be deficient in both flexure and shear. This paper deals with these deficiencies and investigates the behaviour of flexural and shear deficient beams strengthened with externally bonded FRP plates.

It is universally accepted that the flexural failure of a flexure-deficient RC beam is different from the shear failure of a shear-deficient beam. Flexural failure is gradual and characterised by the excessive flexural cracks and yielding of steel reinforcement (or concrete crushing) whereas shear failure appears to be sudden and it is signified by proliferation of diagonal shear cracks. It is a common practice that bottom plates are applied to flexure-deficient RC beams and side plates are used on sheardeficient beams.

Considerable research worldwide has come to the conclusion that FRP plates when applied to bottom of $\mathrm{RC}$ beam may enhance its flexural behaviour and shear performance of RC beam may be altered by bonding side FRP plates. Numerous papers highlighting the performance of $\mathrm{RC}$ beams strengthened in flexure by bonding bottom FRP sheets or plates have been widely published in recent decades. A general experimental finding of reduced deflection and enhanced loading capacity was noticed provided that the FRP plates or sheets were prop- 
erly anchored [3-7]. Almusallam and Al-Salloum [8] studied RC beams strengthened with bottom FRP plates and they indicated that the beam's moment capacity and flexural failure mode were controlled by the thickness of FRP plate. However, in the experiment, side plates were also incorporated in the specimens so as to eliminate the peeling failure of FRP plates but this effect on the beam's performance was not mentioned.

In the meantime, the behaviour of $\mathrm{RC}$ beam strengthened in shear by bonding side FRP plates has been reported in many studies. In 2000, Kachlakev and McCurry [9] studied four full-scale RC beams which were replicated from an existing bridge. The original beam was shear-deficient, and in order to upgrade the beam, side FRP plates and bottom FRP plates were used. They found, from the experimental data, that addition of side plates increased the beam's capacity by $200 \%$ but a $31 \%$ enhancement was recorded when only bottom plates were used. Khalifa and Nanni [10] tested 12 fullscale RC beams with shear deficiencies and they used carbon FRP to strengthen the beams. They found that the contribution of side carbon FRP plates was not proportional with the amount of FRP; a $150 \%$ increase in amount of side carbon FRP side plate led to only $10 \%$ increase in beam's shear strength. They also found that the effect of side plates could be affected by the shear span/depth ratio. Pellegrino and Modena [11] also carried out tests on 11 shear-strengthened $\mathrm{RC}$ beams with and without transverse reinforcement and improvement in beam's shear capacity was noted again. The change in failure mode after side strengthening was also mentioned and they suggested the side plates must be anchored to enhance their effectiveness.

So far, not much work has been found on studying the performance of structurally deficient $\mathrm{RC}$ beams with simultaneous application of side and bottom plates. Present experiments involve testing flexure-deficient only, shear-deficient only, and flexure-and-shear-deficient RC beams with and without external FRP plate bonding. This paper concludes the experimental results and it is anticipated that the data obtained would help understand the behaviour of structurally deficient $\mathrm{RC}$ beams in terms of flexure and/or shear with application of bottom and side FRP plates.

\section{Outline of experiments}

\subsection{Design of $\mathrm{RC}$ beam specimens}

For the flexural design of RC beams, two possible failure modes of flexural member are considered: (1) yielding of steel reinforcement, together with extensive cracking, before concrete crushing and (2) concrete crushing before yielding of steel reinforcement. It is clear that case (1) occurs for under-reinforced RC beams and case (2) is for over-reinforced sections. They were considered in the design of current flexural members. A balanced section is first analysed and the steel area for a balanced section is calculated. An over-reinforced $\mathrm{RC}$ beam is thus adopted by using a steel area more than that of the balanced section whereas $\mathrm{RC}$ beams are under-reinforced (deficient in flexure) by using a steel area less than that of the balanced section.

For the afore-mentioned failure modes of $\mathrm{RC}$ beams, the shear capacity of the RC beams is assumed to be in excess of the flexural capacity. To provide adequate shear capacity, sufficient number of steel stirrups must be used. In an absence of steel stirrups, shear failure of $\mathrm{RC}$ beam occurs. It is usually characterized by inclined cracks and bridging of diagonal cracks. For the current shear design of RC beams, the shear capacities due to concrete and steel stirrups are calculated and compared with the flexural capacity of the beam. By using less number of steel stirrups (deficient in shear), occurrence of shear failure can be accurately predicted.

In the current study, the structurally deficient RC members in terms of flexure and shear are strengthened by plating a woven composite fabric. When the $\mathrm{RC}$ beam is designed to be flexural-deficient, the woven composite fabric is applied to beam's soffit. When the RC beam is shear-deficient, side plates are added. However, when the RC member is deficient in both flexure and shear, side and bottom plates are then applied.

\subsection{Materials and programme}

A total of $10 \mathrm{RC}$ beams of size $180 \mathrm{~mm}$ wide, 250 $\mathrm{mm}$ high and $2500 \mathrm{~mm}$ long were prepared and tested, which included one over-reinforced RC beam (B1), 3 beams under-reinforced in flexure (F1, F2, F3), 3 beams under-reinforced in shear (S1, S2, S3) and 3 beams under-reinforced in both flexure and shear (FS1, FS2, FS3). It should be noted that the names of the specimens, except $\mathrm{B} 1$, are given according to the type of structural deficiency. $F$ represents the flexure-deficient beam series, $\mathrm{S}$ denotes the shear-deficient specimens and FS is designated for both flexure- and shear-deficient RC members.

The design compressive strength of concrete was $30 \mathrm{MPa}$. To achieve this, ordinary Portland cement concrete mix, with a water/cement ratio of 0,6 and aggregate/cement ratio of 2,63 , was adopted. No coarse aggregate was used, but only fine aggregate of size $10 \mathrm{~mm}$ was incorporated. Details of the concrete mix can be found in Table 1.

Table 1. Concrete mix

\begin{tabular}{c|c|c|c|c}
\hline Materials & Cement & Water & $\begin{array}{c}10 \mathrm{~mm} \\
\text { aggregate }\end{array}$ & Sand \\
\hline $\begin{array}{c}\text { Quantity } \\
\left(\mathrm{kg} / \mathrm{m}^{3}\right)\end{array}$ & 350 & 210 & 1000 & 820 \\
\hline
\end{tabular}

High-strength deformed steel bars of diameters 20 $\mathrm{mm}$ and $12 \mathrm{~mm}$ were used as the main longitudinal reinforcement. The yield strength of high-strength steel bars 
was tested to be $420 \mathrm{MPa}$. The lateral reinforcement, in the form of rectangular stirrups, was made of $6 \mathrm{~mm}$ diameter mild steel round bars. The yield strength of the mild steel bar was found to be $235 \mathrm{MPa}$ and the elastic modulus of all steel bars was determined to be $205 \mathrm{GPa}$. The reinforcement details can be found in Figs 1 \& 2 .

In each of the F, $\mathrm{S}$ and FS series, there were 3 specimens. One of the 3 specimens was prepared without any kind of extemal strengthening. The remaining 2 specimens were strengthened by FRP plates before testing. Bottom plates were applied to F series, sides plates were used in S series, and both bottom and side plates were adopted in FS series.

A woven composite fabric was used to strengthen structurally deficient RC beams. The fabric consists of glass fibre yarns in its longitudinal direction and a mix of glass fibre yarns and aramid yarns in transverse direction. It is unidirectional and highly deformable. It is commonly known as fiberwrap. The longitudinal (main) and transverse tensile strengths are $450 \mathrm{MPa}$ and $41 \mathrm{MPa}$ respectively. Along the main glass fibre direction, the elastic modulus is $22,46 \mathrm{GPa}$ and the ultimate strain is 0,02 . To facilitate external strengthening, the woven composite fabric was tailored to small straps of two different dimensions, namely $140 \mathrm{~mm} \times 2100 \mathrm{~mm}$ for bottom plating and $80 \mathrm{~mm} \times 210 \mathrm{~mm}$ for side plating. Positions of fibre straps can be seen in Fig 3. It is noteworthy that the direction of glass fibre yarns was parallel to the longer side of the strap. For perfect bonding, the woven composite fabric was saturated with epoxy, it was then
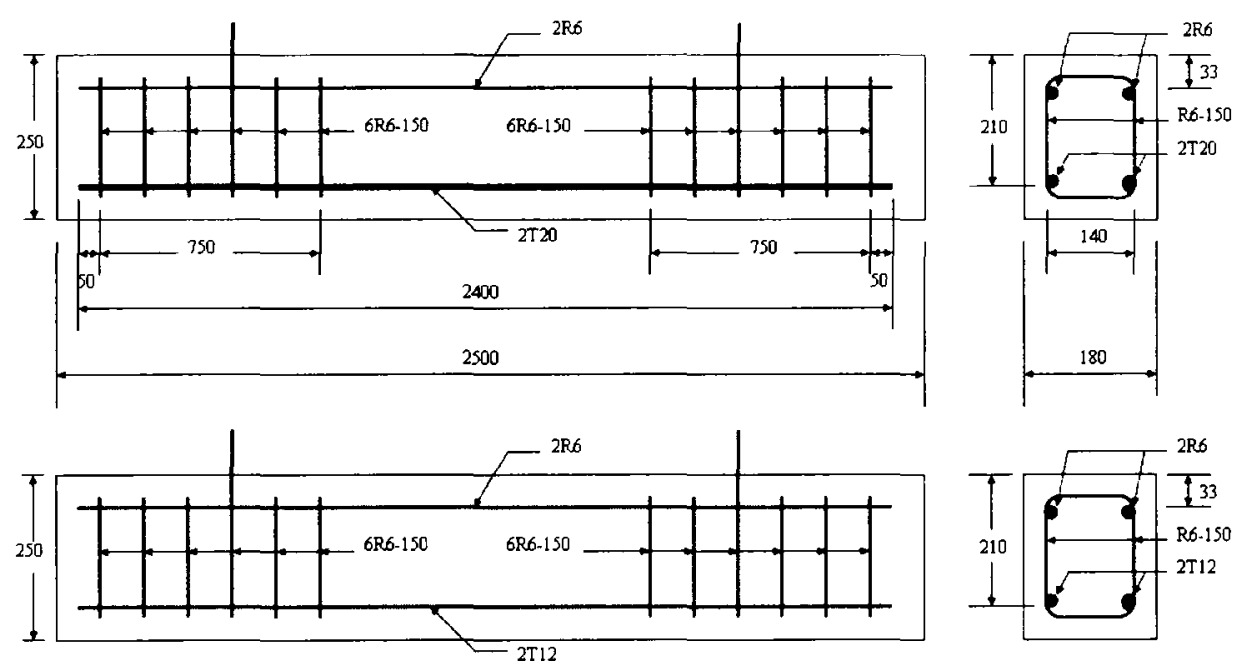

Fig 1. Design for $\mathrm{B} 1$ and $\mathrm{F}$ series specimens (top: $\mathrm{Bl}$; bottom: $\mathrm{F} 1$ to $\mathrm{F} 3$ )
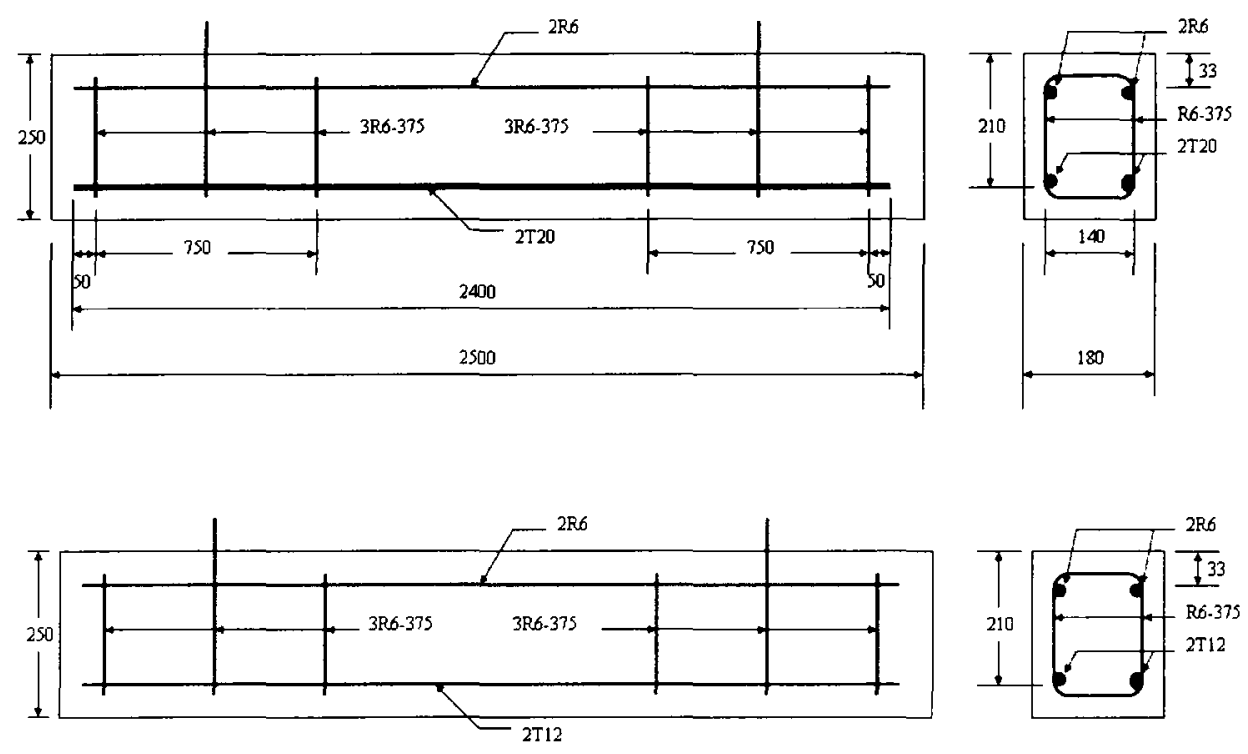

Fig 2. Design for $S$ and SF series specimens (top: $S 1$ to S3; bottom: FS1 to FS3) 
applied on the pre-roughened concrete surface. The epoxy used was a general purpose one with an equal amount of resin and hardener. It had a working time of $2 \mathrm{hr}$ and a curing time of $24 \mathrm{hr}$. The tensile strength of epoxy is $20 \mathrm{MPa}$ and its tensile elastic modulus is $4 \mathrm{GPa}$. When the FRP plate was still wet, air bubbles were driven out to avoid initial imperfections and one day was allowed for setting and hardening. Saturated woven composite fabric was transparent.

Reinforcement details of the $10 \mathrm{RC}$ beam specimens, including internal and external reinforcement, are listed in Table 2. Furthermore, a series of concrete cubes of size $100 \mathrm{~mm}$ were cast together with the beam specimens to give the actual concrete strength at the day of testing.

Table 2. Beam reinforcement details

\begin{tabular}{llll}
\hline $\begin{array}{l}\text { Beam } \\
\text { No }\end{array}$ & $\begin{array}{l}\text { Main } \\
\text { reinforcement }\end{array}$ & $\begin{array}{l}\text { Shear } \\
\text { reinforcement }\end{array}$ & $\begin{array}{l}\text { Strengthening } \\
\text { system }\end{array}$ \\
\hline B1 & 2 T20 & R6-150 & Nil \\
F1 & 2 T12 & R6-150 & Nil \\
F2 & 2 T12 & R6-150 & Bottom FRP plate \\
F3 & 2 T12 & R6-150 & Bottom FRP plate \\
\hline S1 & 2 T20 & R6-375 & Nil \\
S2 & 2 T20 & R6-375 & Side FRP plates \\
S3 & 2 T20 & R6-375 & Side FRP plates \\
\hline FS1 & 2 T12 & R6-375 & Nil \\
FS2 & 2 T12 & R6-375 & Bottom and side \\
& & & FRP plates \\
FS3 & 2 T12 & R6-375 & Bottom and side \\
& & & FRP plates \\
\hline
\end{tabular}

\subsection{Loading setup and measurements}

Testing of beam specimens was conducted under four-point bending condition. A $250 \mathrm{kN}$ actuator, which was connected to a steel spreader, was used to load all the beam specimens. To better capture the failure point, the actuator was adjusted to displacement-controlled mode. Each of the $2500 \mathrm{~mm}$ long specimens was tested over a span of $2214 \mathrm{~mm}$ with a shear span of $707 \mathrm{~mm}$ at both ends, leaving a constant bending region of $800 \mathrm{~mm}$.

To monitor the performance of specimens, linear variable differential transformer (LVDT) transducers were used to measure the transverse displacement at the beam midspan. Electronic strain gauges of gauge length $90 \mathrm{~mm}$ were installed on surface of concrete and FRP plate, if any, to trace the strain variations during the loading course. Loading details and position of strain gauges and FRP plates are illustrated in Fig 3.

\section{Results \& discussion}

\subsection{Failure patterns}

Control beam $\mathrm{Bl}$ was failed by a diagonal shear crack. As Bl was designed properly in terms of shear and flexure, present failure mode indicates that the shear capacity of the beam is lower than its flexural capacity and thus shear type of failure occurs first.

As expected, failures of under-reinforced beam Fl was due to excessive vertical cracks at the soffit of the beam. The cracks were distinct and large crack spacing was observed. It is a typical kind of flexural beam failure. However, when bottom FRP plates were added, the failure mode was changed to a shear type with extensive cracking pattern. Bottom FRP plate debonding was observed just before the occurrence of the diagonal shear crack. The major diagonal shear crack was originated from the concrete at the tip of FRP debonding region and reached the loading point eventually. All other cracks, with small crack spacing, propagated up to about $4 / 5$ of the beam depth. Figs 4 and 5 show the failures of beam $F 1$ and $F 2$ respectively.

Beam S1 was under-designed in terms of shear and its failure is a standard shear type with diagonal cracking. It should be noted the depth of crack, apart from the major diagonal cracking, is about one-half of the beam depth (see Fig 6). When side FRP plates were bonded, the development of diagonal shear cracks was suppressed [12] and flexural failure type by crushing of concrete in the compression zone became the dominant mode (see Fig 7). The side FRP plates remained virtually intact after test. It is thought that, without any improvement on concrete compressive capacity, additional shear capacity provided to the beams under the action of side plates increases the likelihood of beam failure by concrete crushing. The failure occurred suddenly without any sign of warning. Similar results were obtained by Spadea et al [13]. It was also found that the beam specimens with side strengthening exhibited a larger deflection than the unstrengthened one.

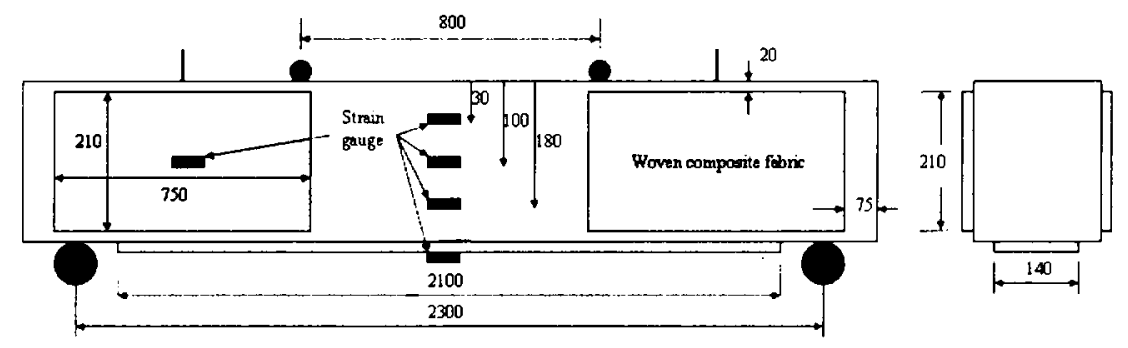

Fig 3. Loading and instrumentation details for FS series specimens 
For the FS series beam specimens, F1 was deficient in terms of shear and flexure. After the test, the beam failed in a shear type with a diagonal shear crack. As indicated in Fig 8, the crack spacing and crack width inside the constant bending region were very large. It was very difficult to predict the failure mode before the failure of the beam reached. Based on the observations of beam before and after failure, it is suggested that the shear capacity of FSI is just marginally smaller than its flexural capacity. After bonding of side and bottom FRP plates, the beam can sustain more loading and the failure mode was changed. Just before failure, very large vertical cracks existed in the constant bending region. The previous diagonal crack was inhibited by the side plates, only minor concrete cracks were found in the shear regions. At failure, partial debonding of bottom plate happened as indicated in Fig 9. The failure was sudden and explosive. After examination of the debonded plate, a small piece of concrete in the constant bending region was attached to the bottom plate and very minimal concrete debris was found elsewhere. The side FRP plates remained intact again.

\subsection{Ultimate load results}

All the tests were carried out at the age of 99 days and the compressive strength of plain concrete cubes varied between 28,2 $\mathrm{MPa}$ and $35,3 \mathrm{MPa}$. The numerical results of the load test are summarised in Table 3 .

Among all unstrengthened beam specimens, B1 shows the highest ultimate load $(120 \mathrm{kN})$ and shear-deficient beam Sl $(105 \mathrm{kN})$ gives a higher load than flexure-deficient beam F1 $(73 \mathrm{kN})$. It is interesting to note that the load capacities of F1 and FS1 $(73 \mathrm{kN})$ and their failure modes are equal. This indicates that when $12 \mathrm{~mm}$ steel bars are used as main reinforcement in the present design beam dimensions, the reduction in stirrup spacing from $150 \mathrm{~mm}$ to $375 \mathrm{~mm}$ is insignificant; the flexure deficiency still dictates the failure mode.

As shown in Table 3, beam specimens with external strengthening achieve more than $35 \%$ increase in ultimate load when compared to the corresponding structurally deficient beams without strengthening. However, only side application of FRP plates on shear-deficient beams S2 and S3 $(165 \mathrm{kN})$ promotes the load capacity to more than that of $\mathrm{Bl}(120 \mathrm{kN})$. This trend is consistent with the past experimental data $[10,11]$. The result suggests that use of side plates on shear-deficient beam appears to be more effective than using bottom plate on flexure-deficient one under current experimental settings [9].

When the results for F series and FS series are compared, the contributions from the external plates are found to be $33,25 \mathrm{kN}$ (mean value) for $\mathrm{F}$ series and $27,5 \mathrm{kN}$ (mean value) for FS series. The reduced contribution from full external plate strengthening indicates that the addition of side FRP plates so as to enhance shear capacity may cause adverse effect to the beam's performance when bottom plates have been used.

Results also imply that when the beam is underdesigned or the load requirement is increased, the selection in using external plate strengthening method must be very careful. For the flexure-deficient beams, addition of one layer of FRP plate at the beam's soffit may not be able to compensate the reduction in beam's flexural capacity from over-design to under-design condition; and the shear capacity of flexural strengthened beam may govern the beam's behaviour. Likewise, when the beam is deficient in shear and flexure, simultaneous use of side and bottom FRP plates may not necessarily recover the loss in beam's capacity. The weakest failure mode will dictate the performance. In the present case, side plates promote the capacity of shear-deficient beam simply because (1) side FRP plates contribute to the shear capacity of the beam; and (2) concrete crushing failure mode displays the lowest load capacity after side plating.

Therefore, one must note that the using of plate bonding to recover or rehabilitate structurally deficient beams should be accompanied with detailed calculations. The anticipated failure mode is not always with the lowest capacity, in particular when external strengthening has

Table 3. Experimental results

\begin{tabular}{llll}
\hline $\begin{array}{l}\text { Beam } \\
\text { No }\end{array}$ & $\begin{array}{l}\text { Concrete cube strength at } \\
\text { test }(\mathrm{MPa}) \\
\text { (mean of } 3 \text { samples) }\end{array}$ & $\begin{array}{l}\text { Ultimate load } \\
(\mathrm{kN})\end{array}$ & $\begin{array}{l}\text { Failure } \\
\text { mode }\end{array}$ \\
\hline B1 & 33,6 & 120 & $\begin{array}{l}\text { diagonal shear cracks } \\
\text { flexural cracks } \\
\text { F1 }\end{array}$ \\
34,3 & 73 & shear cracks with soffit plate debonding \\
F2 & 31,4 & 102,5 & shear cracks with soffit plate debonding \\
F3 & 30,3 & 110 & diagonal shear cracks \\
\hline S1 & 32,9 & 105 & concrete crushing \\
S2 & 31,9 & 165 & concrete crushing \\
S3 & 35,3 & 165 & flexural cracks \\
\hline FS1 & 31,0 & 73 & flexural cracks with soffit plate debonding \\
FS2 & 32,3 & 100 & flexural cracks with soffit plate debonding \\
\hline FS3 & 28,2 & 101 &
\end{tabular}


been carried out. Plate bonding changes the beam's failure mode and this new mode may possibly occur when the load is just marginally greater than the original beam's capacity.

\subsection{Load-deflection curves}

In order to investigate the deformation capacity of strengthened beam specimens, the load-deflection curves are plotted and presented in Figs 10 to 13 .

In Fig 10, the beams Bl and SI show virtually no ductility whereas Fland FSlgive large deformation before failure. This is largely dependent upon their failure modes, shear failure mode is normally sudden and thus brittle, whereas flexural failure mode is usually gradual and exhibits a displacement plateau. FSl shows larger deformation than $\mathrm{Fl}$ at the same ultimate load. This reflects that using a smaller stirrup spacing inside a flexure-deficient beam may enhance the deformation capacity.

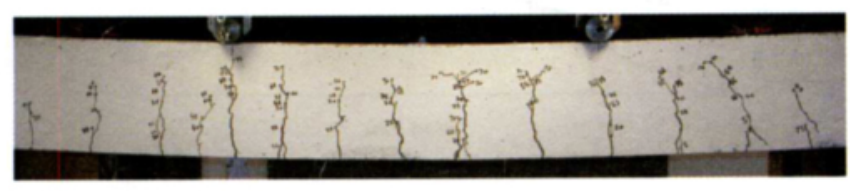

Fig 4. Failure of $\mathrm{F} 1$

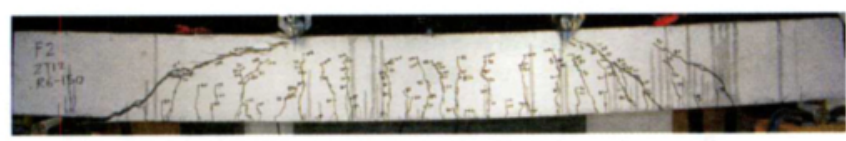

Fig 5. Failure of F2

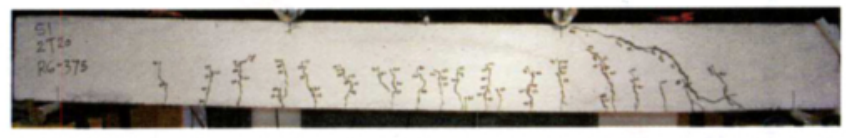

Fig 6. Failure of S1

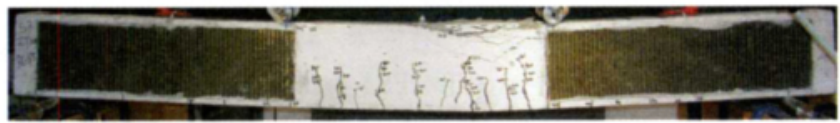

Fig 7. Failure of $\mathrm{S} 3$

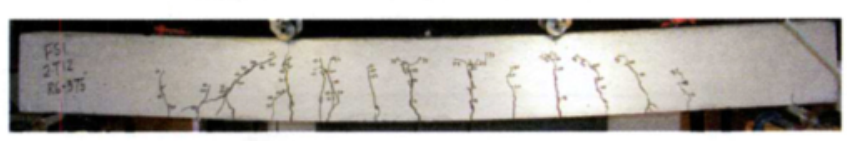

Fig 8. Failure of FS1

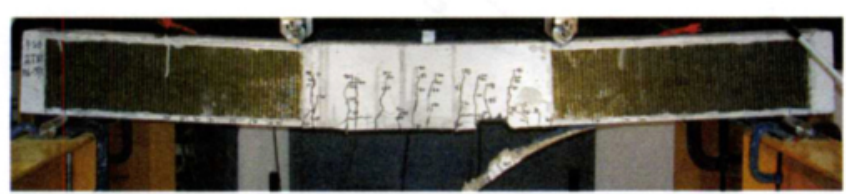

Fig 9. Failure of FS3

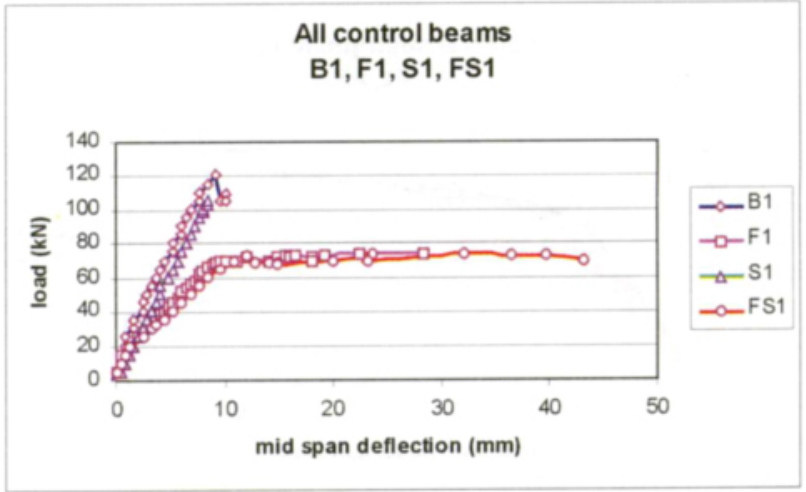

Fig 10. Load-deflection curves for control beams

Fig 11 shows the load-deflection curves for $\mathrm{F}$ series specimens. It is noted that $\mathrm{F} 2$ and $\mathrm{F} 3$ show both increase in maximum load and ductility. It is thus evident that bottom FRP plate contributes to the beam's capacity by restricting the opening of vertical cracks at constant bending region. When the load and deformation are further increased, the developed interfacial shear stress at the concrete-FRP interface exceeds its capacity and then separation of FRP plate occurs. The minor cracks at the shear span may interact with the plate separation and generate a diagonal crack failure. Therefore, this kind of failure mode is always speedy and explosive.

In Fig 12, S2 and S3 provide a peak load and subsequent large post-peak deformation curve. This shows that beams F2 and F3 after side plates bonding alter the beam's performance. The strengthened beams become more deformable as they are no more governed by shear failure but concrete crushing instead. Nevertheless, improvements in both maximum load and ductility are noted again.

However, simultaneous use of side and bottom plates appears to reduce the deformation capacity of the beam although an enhancement in strength is achieved. As shown in Fig 13, full plated beam shows an increase in stiffness before a deflection value of $10 \mathrm{~mm}$. With further deflections, the increase in stiffness for FS2 and FS3 retards, but note that the deflection curve for FSI is almost horizontal. At failure, FS2 and FS3 indicate smaller deflections when compared with that of F1. This may be attributed to the fact that the beam's stiffness is considerably improved particularly in the shear spans.

Thus, if the deformation capacity is the prime factor to be improved in the process of structural strengthening, one should note that simultaneous application of side and bottom plates may be detrimental.

\subsection{Neutral axis depth}

The concrete and FRP plate strains were measured by the strain gauges and they have been used to calculate the neutral axis depth during the course of loading. It should be noted that the strain readings of concrete 


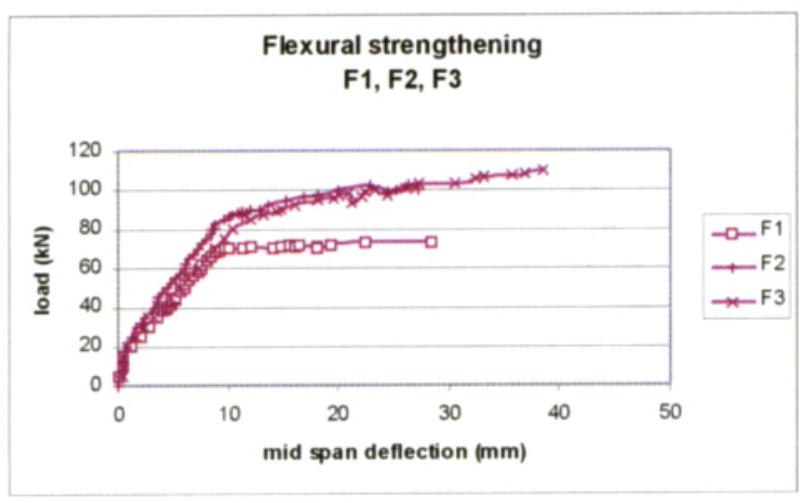

Fig 11. Load-deflection curves for $\mathrm{F}$ series beams

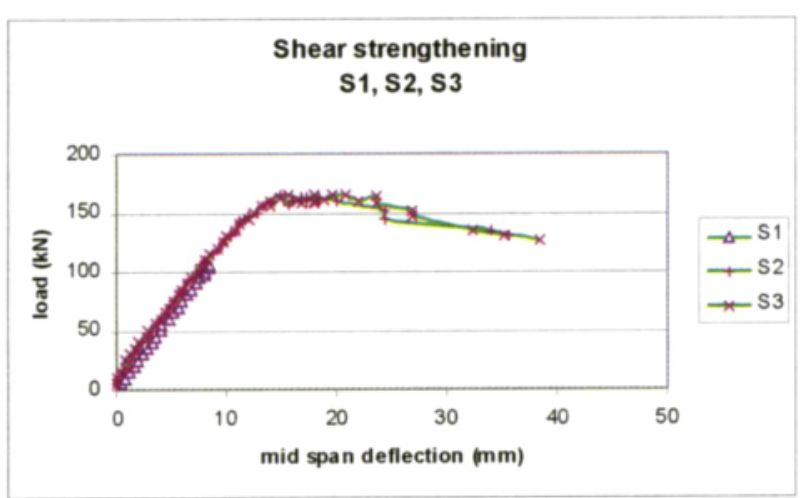

Fig 12. Load-deflection curves for $\mathrm{S}$ series beams

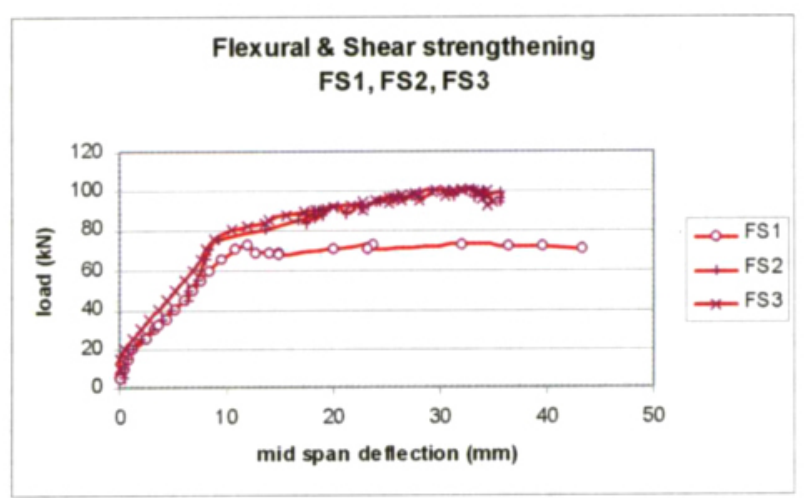

Fig 13. Load-deflection curves for FS series beams

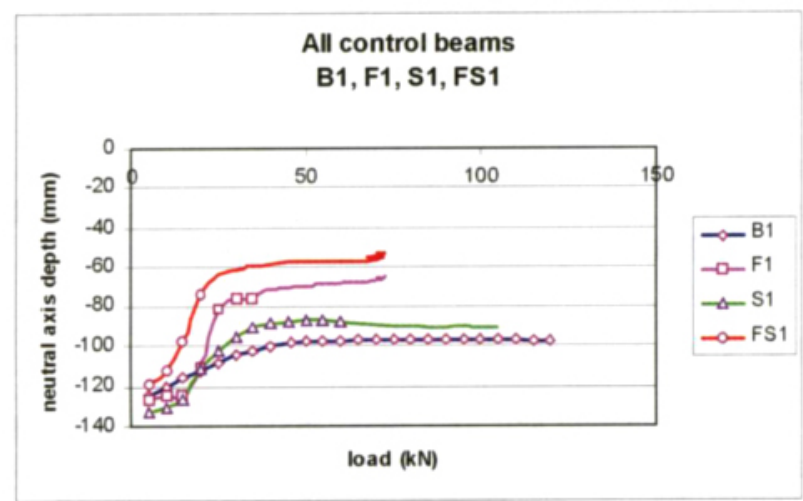

Fig 14. Neutral axes for control beams

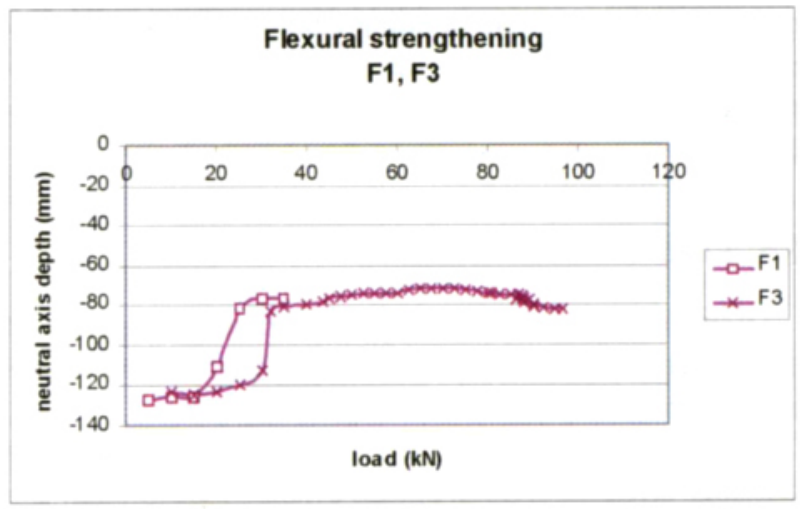

Fig 15. Neutral axes for $F 1$ and $F 3$

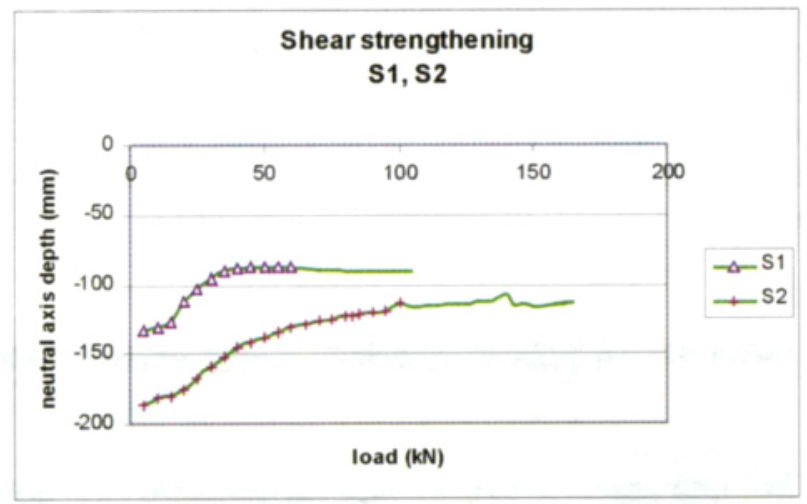

Fig 16. Neutral axes for $\mathrm{S} 1$ and $\mathrm{S} 3$

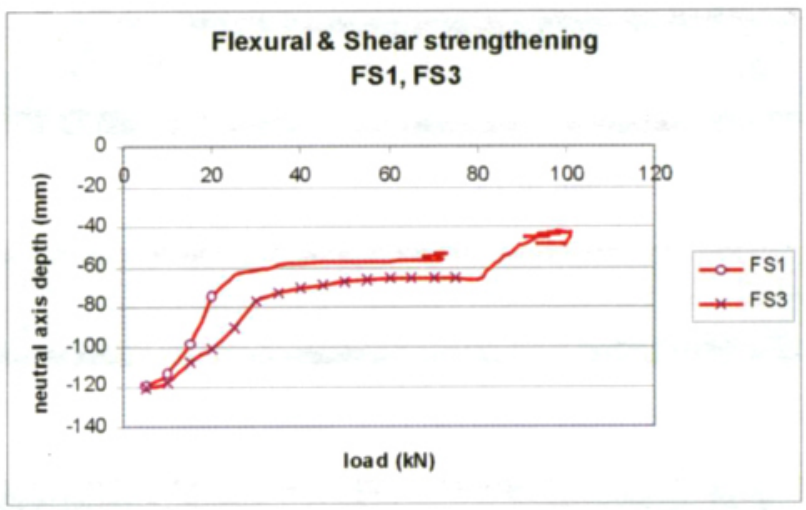

Fig 17. Neutral axes for FS1 and FS3

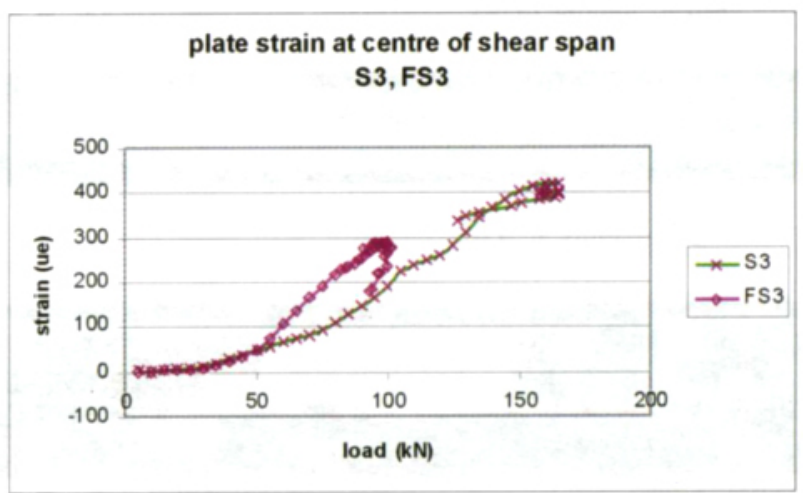

Fig 18. Strain of side FRP plate 
would become erroneous, once the strain gauges were broken by the concrete cracks. However, the neutral axis depth would still be obtained by using the readings of unbroken strain gauges. The method was straightforward and it employed simple trigonometric rules. An approximate linear function was first assumed for the variation of concrete strain along the height of the beam section. Then the position of zero strain could be found easily and this indicated the position of neutral axis depth. Some plots of neutral axis depth against load are present in Figs 14 to 17.

As seen in Fig 14, the neutral axis depths of all control beams shift upwards along with applied load. The shear-controlled beams (Bl and $\mathrm{Sl}$ ) and flexural-controlled beams (F1 and FS1) show similar trend except that the neutral axes for Fl and FSI climb up quickly to lower values at about $15 \mathrm{kN}$ and it is believed to be the cracking load of beam. Then the neutral axes remain unchanged for subsequent load increment.

It is shown in Fig 15 that when the bottom plate is added to flexure-deficient beam, the initial variation is similar but a delay in shift of neutral axis is found. Subsequently, the plated beam can sustain more force at a constant neutral axis depth.

As seen in Fig 16, the neutral axes for unplated and plated shear deficient beams start at different depths, this difference is thought to be due to the increase in beam's stiffness by addition of side FRP plates. The shift-up of neutral axis for the side plated beam (S2) appears to be more gradual and it climbs to a maximum height at failure. This suggests that the presence of side plates effectively retards and delays the crack development at midspan.

As seen in Fig 17, the variation of neutral axes for FS1 and FS3 are basically similar to those of F1 and F3 in Fig 15. Addition of side and bottom plates inhibits the crack growth and gives rise to lower neutral axis depth. After $80 \mathrm{kN}$, partial debonding of FRP plate leads to development of crack at midspan and thus results in sudden rise of neutral axis.

\subsection{GFRP strain}

The side FRP plate strain gauge readings are plotted in Fig 18. It is interesting to note in Fig 18 that side FRP plate strain increases at a faster rate and drops at a lower value for FS3 when compared to those of S3. It is noted that FS3 and S3 are different in terms of the main reinforcement, 2T20 was used in S3, whereas 2T12 together with bottom FRP plate were used in FS3. It is useful to recall the behaviour of $\mathrm{Bl}$ and $\mathrm{F} 3$ (shear reinforcement is the same) that F3 gives reduced load capacity but enhanced deflection, whereas $\mathrm{B} 1$ gives a higher load but less deflection. In the present case, the shear reinforcements of S3 and FS3 are not changed, the properties of $\mathrm{B} 1$ and $\mathrm{F} 2$ again come into play. FS3 (analogous with F3) shows a reduced maximum load and S3 (analogous with B1) gives a higher maximum load.
The reduced strain values in FS3 suggest that the stiffness of beam after simultaneous application of side and bottom FRP plates increases, in particular in its shear span. This further proves the previously stated reason for reduced deflection for FS3.

\section{Conclusions}

Based on the test results of the structurally deficient $\mathrm{RC}$ beams, the following conclusions are drawn. It should be noted that these conclusions are valid for the structurally deficient RC beams strengthened with FRP plates which are made of woven composite fabrics.

- Application of external plate on structurally deficient beams may alter its failure mode.

- The anticipated failure mode of structurally deficient beam is not always with the lowest capacity when external strengthening is done.

- The effect of using side plates on shear-deficient beams appears to be more effective than using bottom plates on flexure-deficient beams.

- Use of side plates on shear-deficient beams increases the likelihood of beam failure by concrete crushing if no improvement on concrete compressive capacity is attained.

- Addition of side FRP plates may cause adverse effect to the beam's performance when bottom plates have been used.

- Simultaneous use of side and bottom plates appears to reduce the deformation capacity of the beam.

- There is a delay in shifting of neutral axis when bottom plate is added to flexure-deficient beam.

- The neutral axes start at different depths for unplated and plated shear-deficient beams, and the shift-up of neutral axis for the plated one appears to be more gradual.

When both side and bottom plates are used, the stiffness of beam increases and gives rise to reduction in FRP side plate strain values.

\section{Acknowledgements}

The work described in this paper was fully supported by a grant from the City University of Hong Kong (Project No 9030935). The authors would like to acknowledge technical support from the Heavy Structures Testing Laboratory in the City University of Hong Kong. Thank is also extended to $\mathrm{L} \& \mathrm{M}$ Composites Inc. for providing composite materials.

\section{References}

1. Clarke J. L. Alternative Materials for the Reinforcement and Prestressing of Concrete, Chapman \& Hall Inc., Chapter 7, 1993, p. 151-171.

2. Uomoto T., et al. Use of fiber reinforced polymer composites as reinforcing material for concrete. Journal of 
Materials in Civil Engineering, ASCE, Vol 14, No 3, 2002, p. 191-209.

3. Meier U. and Kaiser H. Strengthening of structures with CFRP laminates. In: Proc. Advanced Composites Materials in Civil Engineering Structures, ed. by lyer S. L. and Sen R., Las Vegas, Nevada, USA, 1991, p. 224-232.

4. Quantrill R. J., et al. Experimental and analytical investigation of FRP strengthened beam response: Part I. Magazine of Concrete Research, Vol 48, No 177, 1996, p. 331342.

5. Nanni A. and Glad W. Strengthening of RC flexural members with FRP laminates. In: Proc. Repair and Rehabilitation of Reinforced Concrete Structures: The State of Art, ed. by Silva-Araya W. F. et al., Maracaibo, Venezuela, 1997, p. 144-154.

6. Ganga Rao H. V. S. and Vijay P. V. Bending behaviour of concrete beams wrapped with carbon fabric. Journal of Structural Engineering, ASCE, Vol 124, No 1, 1998, p. 310

7. Grace N. F., et al. Strengthening reinforced concrete beams using fiber reinforced polymer (FRP) laminates. $A C I$ Structural Journal, Vol 96, No 5, 1999, p. 865-874.
8. Almusallam T. H. and Al-Salloum Y. A. Ultimate strength prediction for RC beams externally strengthened by composite materials. Composites: Part B, Vol 32, 2001, p. 609619.

9. Kachlakev D. and McCurry D. D. Behaviour of full-scale reinforced concrete beams retrofitted for shear and flexural with FRP laminates. Composites: Part B, Vol 31, 2000, p. $445-452$.

10. Khalifa A. and Nanni A. Rehabilitation of rectangular simply supported RC beams with shear deficiencies using CFRP composites. Construction and Building Materials, Vol 16, 2002, p. 135-146.

11. Pellegrino C. and Modena C. Fiber reinforced polymer shear strengthening of reinforced concrete beams with transverse steel reinforcement. Journal of Composites in Construction, ASCE, Vol 6, No 2, 2002, p. 104-111.

12. Leung $H$. Y. and Balendran R. V. The effect of woven fabric on shear capacity of RC beams. In: Proc. of the Second World Engineering Congress- WEC2002, Kuching, Sarawak, Malaysia, 22-25 July, 2002.

13. Spadea G., et al. Optimizing the performance characteristics of beams strengthened with bonded CFRP laminates. Materials \& Structures, Vol 33, 2000, p. 119-126. 